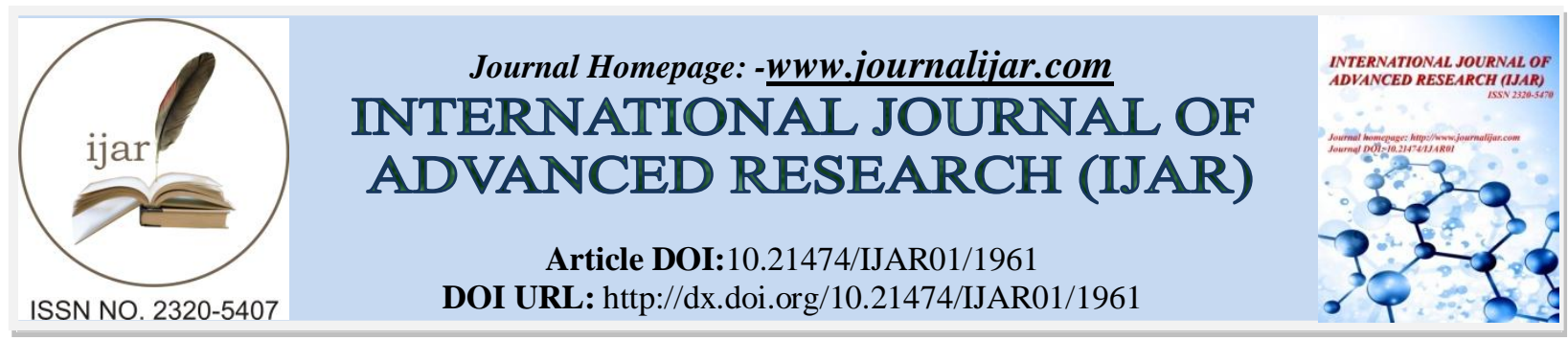

RESEARCH ARTICLE

\title{
IRRITABLE BOWEL SYNDROME AMONG EMPLOYED WOMEN IN ARAR CITY, NORTHERN SAUDI ARABIA.
}

Marzook Khalid Alshammari ${ }^{1}$, Nasser Ghadeer ALshamari ${ }^{2}$, Abdullah Olum Alshammari ${ }^{2}$, Mahmoud Mohammed Alsharif ${ }^{2}$, Jazzaa Hammad Alshammari ${ }^{2}$, Alwaleed Oqab Altimyat ${ }^{2}$, Abdullah Barghash k Alanazi ${ }^{2}$, Hanan Saleh A Alruwaili ${ }^{3}$, Entsar Owaid Alanazi ${ }^{3}$ and Nagah Mohamed Abo el-Fetoh ${ }^{4}$

1. Family Medicine resident.

2. Faculty of medicine, northern border university.

3. Intern, Faculty of Medicine, Northern border University.

4. Associate Prof., Community Medicine Department, Faculty of Medicine, Sohag University, Egypt and Northern border University, KSA.

\section{Manuscript Info}

Manuscript History

Received: 22 August 2016

Final Accepted: 12 September 2016

Published: November 2016

Key words:-

Irritable bowel syndrome; socio-

demographic variables; prevalence;Arar,

Kingdom of Saudi Arabia.

\section{Abstract}

Background:- The prevalence and epidemiological features of irritable bowel syndrome (IBS) have not been properly investigated in adult working women in Arar, Kingdom of Saudi Arabia. Also, worldwide there is limited knowledge about the exact prevalence of IBS and its relation to stressful life of working women. The aim of the study was to determine the prevalence of IBS among Educated and Working Women of Arar, KSA; and to discover undiagnosed cases of IBS and to investigate the role of socioeconomic and behavioral factors on IBS prevalence in this group of individuals.

Methods:- This is a cross-sectional study in adult working women living in Arar city, the capital of the Northern province of Saudi Arabia. Demographic characteristics and common gastrointestinal symptoms were assessed using a self-administered modified Persian version of the Rome III questionnaire. The questionnaire was administrated to working women of Arar city; a population consisting of (207) women (whose mean age was $36 \pm 7.5$ ) years old.

Results:- In 207 subjects aged 20-60 years the overall prevalence of IBS was $35.7 \%$. In multivariate analysis, there is significant effect of average family income/month $(\mathrm{P}<0.05)$, butno significant effect of age, marital status, sector of working place and educational level on IBS occurrence among the studied working women $(\mathrm{P}>0.05)$.

Conclusion:- IBS is highly prevalent among educated and working women of Arar, KSA and there is significant effect of average family income/month, but no significant effect of age, marital status, sector of working place and educational level on IBS occurrence among those women. Screening of employed women for IBS and psychological problems are recommended. In order to make the working women capable to cope up and overcome the stressors during their work, there is a primary requirement of stress management courses. 


\section{Introduction:-}

Irritable bowel syndrome (IBS) is a functional GI disorder characterized by abdominal pain and altered bowel habits in the absence of specific and unique organic pathology. The diagnosis of IBS is based on clinical findings and the exclusion of other disorder [1].Altered gastrointestinal motility, visceral hypersensitivity, post-infectious reactivity, brain-gut interactions, alteration in gut microbiota, food sensitivity, dietary intakes, and intestinal inflammation have been linked to the pathogenesis of IBS [2].

Irritable bowel syndrome (IBS) is one of the most frequently diagnosed gastrointestinal (GI) disorders in primary care and gastroenterology practices, despite the fact that many suffer symptoms without knowing their diagnosis or seek for medical consult [2].Most people with IBS have mild symptoms. Many people don't recognize IBS symptoms. Not all individuals with IBS symptoms seek medical care for their symptoms. [3].

The worldwide prevalence of IBS ranges from 5.7\% to 34\% [4], usually varying significantly between countries according to the diagnostic criteria used [5]. Currently, the Rome III criteria are the most common method for diagnosing IBS [6]. Based on the Rome III criteria, the prevalence of IBS has been estimated to range from $10 \%$ to $15 \%$ in Western countries, whereas that reported in Asian countries ranged from $1 \%$ to $10 \%$ [7].

Approximately $60 \%$ to $65 \%$ of individuals who report IBS in the community are female [2].

There were not many studies that included both medical and non medical students together. Similar studies about the prevalence of IBS among medical students from South America [2], china [4], and Saudi Arabia [5] revealed prevalence rates of $21 \%, 28.3 \%, 31.8 \%$ consequently.

A study was conducted in Egypt by Ahmed Abdulmajeed et al. in an urban area in Suez governorate from January 2008 to August 2009. 117 individuals were included in this study. Rome II criteria were used for the diagnosis of IBS. The prevalence of IBS among the study sample was $34.2 \%$ [6].

Another study was conducted in Sues, Egypt, aims to explore the prevalence of irritable bowel syndrome (IBS) among Suez Canal university students. Using Rome criteria III IBS module, a total (170) students (whose mean age is $20 \pm 0.82$ ), the prevalence of IBS according to Rome III criteria in Suez Canal University was $22.9 \%$. $23.8 \%$ were diseased in the faculty of commerce while $22.1 \%$ in faculty of medicine. Females in this study represent $64.1 \%$ of the sample, $30.3 \%$ of them were diseased, while males represent $35.9 \%$ about $9.8 \%$ of them were diseased. IBS constipation predominant type was $28.2 \%$, diarrhea predominant type was $15.4 \%$, mixed type was $46.2 \%$, and the un-subtyped cases represent $10.3 \%$ [3].

In a study conducted in Iran to show the prevalence of IBS among adults aged 19-70 years the overall prevalence of IBS was $21.5 \%$. IBS was more prevalent in women than men $(24.0$ vs. $18.3 \%, \mathrm{P}<0.001)$. In multivariate analysis, being married was associated with $27 \%$ increased odds of IBS $(\mathrm{P}<0.05)$. However, IBS was not associated with age $(\mathrm{P}=0.71)$ or educational attainment $(\mathrm{P}=0.61)[8]$.

Little is known about IBS prevalence in Arab countries and specifically among Educated and Working Women, including in Arar, KSA. The sample population chosen is significant because of the lifestyle characteristics that this population experience. Not only are women's relatively restricted in terms of access to a variety of foods but are also exposed to a stress load that accompanies family and work limitations, thereby potentially exacerbating the onset of IBS symptoms. As a result, an epidemiological study investigating IBS among Educated and Working Women in Arar is warranted. Using the Rome III criteria to determine IBS, this study is the first to examine the prevalence and factors associated with IBS among a sample of Educated and Working Women in Arar.

\section{Aim of the study:-}

- To determine the prevalence of IBS among Educated and Working Women; and

- To discover undiagnosed cases of IBS.

- To investigate the role of socioeconomic and behavioral factors on IBS prevalence in this group of individuals. 


\section{Methodology:-}

This is a cross-sectional study in adult working women living in Arar city, the capital of the Northern province of Saudi Arabia.

Using Rome III criteria questionnaire of IBS; which is a self-administrated consists of ten questions assessing the current status of an apparently normal person.Each question can be answered according to a scale describing the frequency of experiencing each symptom.

According to Rome III criteria, IBS is defined as recurrent abdominal pain or discomfort at least 3 days per month in the last 3 months associated with two or more of the following:

1. Improvement with defecation;

2. Onset associated with a change in frequency of stools; and

3. Onset associated with a change in form (appearance of stool).

Also, these criteria should be fulfilled for the last 3 months with symptom onset at least 6 months before diagnosis $[9,10]$.IBS was classified into four subtypes; constipation-predominant, Mixed IBS (IBS-M), diarrhea-predominant IBS and Unsubtyped IBS [11].

The questionnaire was administrated to working women of Arar city; a population consisting of (207) women (whose mean age was $36 \pm 7.5$ ) years old.

Participants were provided with the questionnaire in their working places and they give it back at the same day. Well trained data collecting team were responsible for distributing the questionnaire and providing help while participants filling it.

\section{Ethical considerations:-}

This study was reviewed and approved by the Research Ethics Committee of Faculty of Medicine, Northern Border University. Participants were informed that participation is completely voluntary, and written consent was obtained from each participant before being subjected to the questionnaire and after discussing the objective with the participants. No names were recorded on the questionnaires. All questionnaires were kept safe.

\section{Statistical analysis:-}

Data were analyzed using statistical package for social science (SPSS) version 16.comparison between groups was assessed using the chi-squared test, with a 95\% confidence interval (CI), p-value less than 0.05 was considered statistical significant.

\section{Results:-}

Table (1) illustrates the percentage distribution of IBS and socio-demographic characteristics (Age group, Marital status, Educational level, Working status, Family income) among the studied women, Arar, KSA, as regards the percentage distribution of IBS among the studied group of working women, it is clear from the table that more than third (35.7\%) had the manifestations of IBS according to the Rom III criteria. As regards the age group, the majority of participants (29.5\%) were at the age of 31 to 36 years, about quarter of them (24.6\%) aged of 36 to 40 years, about fifth (19.8\%) aged 20 to 26 years and $16.9 \%$ aged of 26 to 31 years, and only $9.2 \%$ aged 40 years or more.

Regarding marital status, most of the respondents $(70.5 \%)$ were married , more than fifth $(21.3 \%)$ were singles, only $(4.8 \%)$ were divorced and $(3.4 \%)$ were widow.

As regard as Educational Level the majority of cases ( $87.9 \%)$ were university graduates, only $(0.5 \%)$ had completed their primary education, and just $1.9 \%$ had completed their preparatory education, (5.8\%) completed their secondary education, $(1.4 \%)$ of the cases have a master degree and $(2.4 \%)$ of them had doctor degree.

As regards the average family income/month (in SR), the majority of the participants (51.7\%) had 8000 to 15000 , about third (30\%) had 2000 to 8000 , and only $12.6 \%$ had less than 2000 however $5.8 \%$ had 15000 or more $\mathrm{SR} / \mathrm{month}$. 
As regards the relationship between IBS and socio-demographic variables in the studied participants, it is clear from the table that, there is there is significant effect of average family income/month $(\mathrm{P}<0.05)$, butno significant effect of age, marital status, average family income/month, sector of working place and educational level on IBS occurrence among the studied working women, Arar, KSA (Table 2)

Table 1:-Socio-demographic characteristics and prevalence of irritable bowel syndromeamong the studied women, Arar, KSA, $2016(n=207)$

\begin{tabular}{|c|c|c|}
\hline & No. & $\%$ \\
\hline \multicolumn{3}{|l|}{ Irritable bowel syndrome } \\
\hline - Yes & 74 & 35.7 \\
\hline No & 133 & 64.3 \\
\hline \multicolumn{3}{|l|}{ Age } \\
\hline $20-$ & 41 & 19.8 \\
\hline $26-$ & 35 & 16.9 \\
\hline $31-$ & 61 & 29.5 \\
\hline - $36-$ & 51 & 24.6 \\
\hline 40 years or more & 19 & 9.2 \\
\hline \multicolumn{3}{|l|}{ Marital status } \\
\hline - Single & 44 & 21.3 \\
\hline - Married & 146 & 70.5 \\
\hline - Widow & 7 & 3.4 \\
\hline - Divorced & 10 & 4.8 \\
\hline \multicolumn{3}{|l|}{ Educational level } \\
\hline - Primary & 1 & 0.5 \\
\hline - $\quad$ Preparatory & 4 & 1.9 \\
\hline - Secondary & 12 & 5.8 \\
\hline - University & 182 & 87.9 \\
\hline - Master degree & 3 & 1.4 \\
\hline - Doctor degree & 5 & 2.4 \\
\hline \multicolumn{3}{|c|}{ Average family income/month (in SR) } \\
\hline$\cdot \quad>2000$ & 26 & 12.6 \\
\hline - 2000 - & 62 & 30.0 \\
\hline - 8000 - & 107 & 51.7 \\
\hline - 15000 or more & 12 & 5.8 \\
\hline
\end{tabular}

Table 2:-The relationship between socio-demographic characteristics and Irritable bowel syndrome among the studied women, Arar, KSA.

\begin{tabular}{|c|c|c|c|c|c|}
\hline \multirow[t]{2}{*}{ Parameter } & \multicolumn{2}{|c|}{ Irritable bowel syndrome } & \multirow[t]{2}{*}{ Total } & \multirow[t]{2}{*}{ chi } & \multirow[t]{2}{*}{$\mathrm{P}$ value } \\
\hline & No $(n=133)$ & Yes $(n=74)$ & & & \\
\hline \multicolumn{6}{|l|}{ Age group } \\
\hline . 20- & $24(18.0)$ & 17(23.0) & $41(19.8)$ & \multirow[t]{5}{*}{7.478} & \multirow[t]{5}{*}{0.11} \\
\hline - 26- & $21(15.8)$ & $14(18.9)$ & $35(16.9)$ & & \\
\hline - $31-$ & $43(32.3)$ & $18(24.3)$ & $61(29.5)$ & & \\
\hline - $36-$ & $37(27.8)$ & $14(18.9)$ & $51(24.6)$ & & \\
\hline - 40 years or more & $8(6.0)$ & 11(14.9) & $19(9.2)$ & & \\
\hline \multicolumn{6}{|l|}{ Marital status } \\
\hline - Single & $31(23.3)$ & 13(17.6) & $44(21.3)$ & \multirow[t]{3}{*}{6.40} & \multirow[t]{3}{*}{0.06} \\
\hline - $\quad$ Married & $87(65.4)$ & $59(79.7)$ & $146(70.5)$ & & \\
\hline - Widow\& Divorced & $15(11.3)$ & $2(2.8)$ & $17(8.2)$ & & \\
\hline \multicolumn{4}{|c|}{ Average family income/month (in SR) } & & \\
\hline$\cdot \quad>2000$ & 17(12.8) & $9(12.2)$ & $26(12.6)$ & \multirow[t]{4}{*}{7.60} & \multirow[t]{4}{*}{5.055} \\
\hline - $2000-$ & $48(36.1)$ & 14(18.9) & $62(30.0)$ & & \\
\hline - $8000-$ & $62(46.6)$ & $45(60.8)$ & $107(51.7)$ & & \\
\hline - 15000 or more & $6(4.5)$ & $7(9.4)$ & $13(6.3)$ & & \\
\hline
\end{tabular}




\begin{tabular}{|c|c|c|c|c|c|}
\hline \multicolumn{4}{|l|}{ Working status } & & \\
\hline - Ministry of education & $81(60.9)$ & $43(58.1)$ & $124(59.9)$ & \multirow[t]{4}{*}{2.371} & \multirow[t]{4}{*}{0.061} \\
\hline - Health sector & $25(18.8)$ & $19(25.7)$ & $44(21.3)$ & & \\
\hline - Govern sector & $16(12.0)$ & $9(12.2)$ & $25(12.1)$ & & \\
\hline - Private sector & $11(8.3)$ & $3(4.1)$ & $14(6.8)$ & & \\
\hline \multicolumn{6}{|l|}{ Educational level } \\
\hline - Primary & $0(0.0)$ & $2(2.8)$ & $2(1.0)$ & \multirow[t]{6}{*}{10.2} & \multirow[t]{6}{*}{0.069} \\
\hline - $\quad$ Preparatory & $3(2.3)$ & $1(1.4)$ & $4(1.9)$ & & \\
\hline - Secondary & $11(8.3)$ & $1(1.4)$ & $12(5.8)$ & & \\
\hline - University & $116(87.2)$ & $66(89.2)$ & 182(87.9) & & \\
\hline - Master degree & $2(1.5)$ & $1(1.4)$ & $3(1.4)$ & & \\
\hline - Doctor degree & $1(0.8)$ & $4(5.4)$ & $5(2.4)$ & & \\
\hline
\end{tabular}

\section{Discussion:-}

This study was conducted to determine the prevalence of IBS among adult educated and working women in Arar city, Northern Saudi Arabia, through the Rome III criteria IBS module.

In the present study, IBS prevalence of $35.7 \%$ was found and there is no significant effect of age, marital status, average family income/month, sector of working place and educational level on IBS occurrence among the studied working women.

Our reported prevalence is different from other studies. In Egypt, Suez canal study reported a prevalence among women of $41.1 \%$ using Rom III criteria [6]. With no significant difference among different age groups which is in accordance with our findings. On the other hand, in Iranian study with subjects aged 19-70 years the prevalence of IBS among adult women was $24.0 \%$ married was associated with $27 \%$ increased odds of IBS $(\mathrm{P}<0.05)$. However, IBS was not associated with age $(\mathrm{P}=0.71)$ or educational level $(\mathrm{P}=0.61)[8]$.

The current study revealed that there is no significant effect of age, on IBS occurrence among the studied working women. However, the Suez canal study revealed that there was no statistical significant difference between IBS positives and negatives regarding age difference ( $p>0.05$ ), but the IBS prevalence was higher in age group 40-49 years $(48.72 \%)$ [6]. Hungin et al. found that prevalence rates were highest among those aged 25-54 years [12]. Kay et al [13] and Karaman et al [14]found an inverse relationship between age and IBS prevalence, perhaps because individuals might ignore IBS-related symptoms as their organic diseases become more dominant with increased age.

In the present study, it was found that, there is no significant effect of marital status or educational level on IBS occurrence among the studied working women. In Suez canal study, the prevalence of IBS was highest in widow individuals (80\%) this may be due to increasing responsibilities and stressors [6]. Andrews et al. found prevalence was higher among unmarried individuals compared with married (7.7\% vs. 5.9\%) [15].

However, Abdulmajeedet al. can not detect any significant difference according to educational status [6]. These findings are consistent with Karaman et al. that found IBS prevalence did not show any significant difference according to educational status but it was significant regarding the occupational distribution[14].

\section{Conclusion and recommendations:}

IBS is highly prevalent among educated and working women of Arar, KSA and there is significant effect of average family income/month, while no significant effect of age, marital status, sector of working place and educational level on IBS occurrence among those women.Screening of employed women for IBS and psychological problems are recommended. In order to make the working women capable to cope up and overcome the stressors during their work, there is a primary requirement of stress management courses.

\section{Acknowledgment:}

The success and final outcome of this research paper required assistance from many people and I am extremely fortunate to have got this all along the completion of this work. My thanks go to Omar Tabaan Alenezi $\left(6^{\text {th }}\right.$ year Faculty of Medicine, Northern Border University), Tariq Hulayyil Alanazi $\left(5^{\text {th }}\right.$ year Faculty of Medicine, 
Northern Border University), Shadia Abdulrahman Aloufiand Asmaa Hamoud Alruwaili (Intern, NBU)and

Walaa Mohamed Bakr Ali for their cooperation in different steps of the research.

\section{References:-}

1. Jafri, W., Yakoob, J., Jafri, N., Islam, M. and Ali, Q.M. (2005) Frequency of Irritable Bowel Syndrome in College Students. Journal of Ayub Medical College Abbottabad, 17, 9-11.

2. About I.B.S. (2013) What's IBS, Statistics. http://www.aboutibs.org/site/what-is-ibs/facts/statistics

3. Darweesh M. M, Mennat Allah M. Abd El Hameed, Yomna M. Hassan, Khadiga A. Abd El Rheem, Shaza A. Mohamed, Marwa A. Mahdy, Ahmed A. Slwawy, Mona M. Abo El Ftooh (2015): The Prevalence of Irritable Bowel Syndrome among Medical and Non-Medical Suez Canal University Students.Open Journal of Gastroenterology, 2015, 5, 42-48

4. Shen L, Kong H, Hou X. Prevalence of irritable bowel syndrome and its relationship with psychological stress status in Chinese university students. J GastroenterolHepatol. 2009;24:1885-1890. [PubMed]

5. Ibrahim, N.K.R., Battarjee, W.F., Almahdi, S.A., et al. (2013) Prevalence and Predictors of Irritable Bowel Syndrome among Medical Students and Interns in King Abdul-Aziz University, Jeddah, Saudi Arabia. Libyan Journal of Medicine, 8, 21287.

6. Abdulmajeed, A., Rabab, M.A., Sliem, H.A. and Hebatallah, N.E. (2011) Pattern of Irritable Bowel Syndrome and Its Impact on Quality of Life in Primary Health Care Center Attendees, Suez Governorate, Egypt. Pan African Medical Journal, 9, 5.

7. Chang FY, Lu CL, Chen TS. The current prevalence of irritable bowel syndrome in Asia. J NeurogastroenterolMotil. 2010;16:389-400. [PMC free article] [PubMed]

8. Keshteli AH, Dehestani B, Daghaghzadeh H, and Adibi P. Epidemiological features of irritable bowel syndrome and its subtypes among Iranian adults. Ann Gastroenterol. 2015 Apr-Jun; 28(2): 253-258.

9. Thompson WG, Drossman DA, Talley NJ, et al. Rome III diagnostic questionnaire for the adult functional GI disorders (including alarm questions) and scoring algorithm. In Drossman DA, Corazziari E, Delvaux M, et al (eds), Rome III; The functional gastrointestinal disorders, 3rd edn. McLean: Degnon Associates, 2006:917-951.

10. Longstreth GF, Thompson WG, Chey WD, Houghton LA, Mearin F, Spiller RC. Functional bowel disorders. Gastroenterology 2006;130:1480-1491.

11. World Gastroenterology Organization (2009) Global Guideline Irritable Bowel Syndrome: A Global Perspective.

12. Hungin AP, Chang L, Locke GR, Dennis E H, Barghout V. Irritable Bowel Syndrome in the United States: Prevalence, Symptom Patterns and Impact. Aliment PharmacolTher. 2005 Jun 1;21(11):1365-75.[PubMed]

13. Kay L, Jorgensen T, Jensen KH. The epidemiology of irritable bowel syndrome in a random population: prevalence, incidence, natural history and risk factors. J Intern Med. 1994 Jul;236(1):23-30. [PubMed]

14. Karaman N, Trukay C, Yonem O. Irritable bowel syndrome prevalence in city center of Sivas. Turkish Journal of Gastroenterology. 2003;14(2):128-131. [PubMed]

15. Andrews E B, Eaton S C, Hollis K A, Hopkins J S, Ameen V, Hamm L R, Cook S F, Tennis P, Mangel A W. Prevalence and Demographics of Irritable Bowel Syndrome: Results from a Large Web-Based Survey.Alimentary Pharmacology \&Therapeutics. Aliment PharmacolTher. 2005 Nov 15;22(10):93542. [PubMed] 